\title{
An investigation of solar active power filter based on direct power control for voltage quality and energy transfer in grid-tied photovoltaic system under unbalanced and distorted conditions
}

\author{
Ghania Boudechiche*, Mustapha Sarra*, Oualid Aissa** and Jean-Paul Gaubert*** \\ *ETA Laboratory, Department of Electronics, University of Bordj Bou Arreridj, Algeria \\ **LPMRN Laboratory, Department of Electromechanical, University of Bordj Bou Arreridj, Algeria \\ ***Laboratory of Computer Science and Automatic Control for Systems, University of Poitiers, France \\ *Corresponding Author: boudechiche.gh@gmail.com
}

Submitted: 19/11/2019

Revised: $\quad 21 / 10 / 2020$

Accepted: 27/10/2020

\begin{abstract}
This paper discusses a renewable energy system connected to a dual-function power grid through a shunt active power filter to improve the power quality and inject photovoltaic (PV) energy to the power grid in the presence of nonlinear loads. Disturbance rejection for this electrical network is provided by the proposed direct power control (DPC) command. The DPC strategy combines a fractional order PID controller for the regulation of the DC bus voltage with an intelligent method of tracking the maximum power point articulated on the fuzzy logic, reserved to address dynamic weather conditions. The quality of energy is offered by the improved DPC resides in the elimination of the undesirable harmonics of the source currents. Thus, the studied system operates under a power factor near unity with acceptable harmonic distortion, in agreement with the international standard IEEE-519. The overall control of the presented system is assessed under different states of the power source behavior-balanced, unbalanced, and distorted - through simulation using MATLAB/Simulink software. The results demonstrate the performance, robustness, and feasibility of the proposed methods compared to the existing techniques in the literature.
\end{abstract}

Keywords: Active power filter; Direct power control; Disturbance rejection; Fractional order PID regulator; Fuzzy logic MPPT controller.

\section{INTRODUCTION}

The increasing use of nonlinear loads based on power electronics connected to power grids has a negative impact. These devices generate harmonic currents with the resulting consumption of reactive power and degradation of the power factor of the electrical network (Bengourina et al., 2018). To overcome these problems, a remedial solution has been adopted, in which a filtering device, comprising an inverter and a solar panel, is connected and integrated into a shunt with the system: three-phase power source nonlinear load. This combination of a shunt active power filter (APF) associated with a photovoltaic (PV) source results in a clean energy source, effectively improving the quality of energy (Noroozian et al., 2013; Tareen et al., 2017). The shunt active power filter (SAPF) injects a current that opposes the harmonic current emitted by the load to mitigate the effect of harmonics currents and reactive power. So, the delivery 
of the current by the power source remains sinusoidal (Biricik et al., 2014). Many techniques have been reported for the control of APF, and hysteresis current command is a popular method (Sarra et al., 2009). However, this approach cannot ensure a link between the three distinct hysteresis comparators, specific to this command. In addition, this type of regulator leads to operation with a variable switching frequency (Chauhan et al., 2014). To correct these defects, researchers have suggested new methods, such as direct power control (DPC), introduced by Noguchi et al. (1998), which was developed from direct torque control (DTC) intended for electrical machines drives (Bengourina et al., 2018; Aissa et al., 2016). The DPC technique does not require current control loops or a PWM modulator block. The switching table, based on the correction of the active and reactive powers and on the sector indicating the angular position of the source voltage vector, is intended to select the switching states of the converter (Noguchi et al., 1998; Chaoui et al., 2010). In this context, researchers devoted much attention to this table (Krama et al., 2017; Chaoui et al., 2013) for a better performance of DPC. In all cases, DPC is presented by a reference of the zero reactive power and another reference of the active power produced via the proportional-integral (PI) regulator of the converter output voltage (Bengourina et al., 2018; Krama et al., 2017). Nevertheless, both methods suffer from some drawbacks related to the variable switching frequency and high sampling rate (Zhang et al., 2016). To avoid these disadvantages, the direct power control with space vector modulation (DPC-SVM) uses a voltage modulator and linear PI controller in place of a switching table and hysteresis comparators (Malinowski et al., 2004). However, this technique requires coordinate transforms and PI regulator settings. For this reason, some authors suggested another approach, known as the predictive direct power control (P-DPC) (Boukezata et al., 2016). Although this approach yields better accuracy, it requires complex calculations that are sensitive to variations affecting the system parameters (Boukezata et al., 2016; Bouafia et al., 2012). Furthermore, when these control strategies are employed under distorted or unbalanced conditions of the power source, the system performance deteriorates with the increased presence of total harmonic distortion (THD) at the input currents.

This paper discusses a new DPC configuration that is designed to enhance the conventional DPC in terms of power quality and solve the issues of unbalance and contamination of the power source by harmonics. The presented DPC strategy requires zero reactive and active power disturbance references to reject the influence of degraded or distorted grid due to harmonics emitted by the nonlinear load in the PV system. Furthermore, this control strategy is characterized by simple calculations and is capable of maintaining the performance of the system with an acceptable rate of THD under balanced, unbalanced, or disturbed grid voltage conditions. Various control techniques are employed to maintain the DC-link voltage at its reference value. Among those, the conventional PI controller, which is easy to implement, offers good steady-state but poor transient-state response (Sarra et al., 2011; Chaoui et al., 2010). The fractional order PID (FOPID) with two additional degrees of freedom ( $\varepsilon$ and $\eta$ in $\left.\mathrm{PI}^{\varepsilon} \mathrm{D}^{\eta}\right)$, proposed by Oustaloup (1995), presents better dynamic response and a faster response time compared to the conventional PI controller (Oustaloup et al., 1983; Oustaloup et al., 1995). This was the first time that the FOPID controller was incorporated into the DPC. Since solar insolation is variable, several algorithms of maximum power point tracking (MPPT), such as incremental conductance (IC), perturb and observe (PO), and hill-climbing (HC), have been proposed (Ishaque et al., 2013; Kjær, 2012). The tracking algorithm, based on fuzzy logic, is considered as one of the most efficient algorithms (Zadeh, 1965; Ouchen et al., 2016; Benlahbib et al., 2018). In our research, the maximum power point (MPP) is intelligently reached regardless of the degree of change of solar radiation owing to the fuzzy MPPT technique.

The combination of two advanced controllers, the FOPID and fuzzy MPPT, applied to the DPC command with disturbance rejection to control the solar filter of a healthy and infected three-phase electrical network, has been proposed in this paper. MATLAB/Simulink software was used to evaluate our work. By comparing simulation results with those of recently published research, the proposed techniques had clear advantages and satisfactory results under transient and steady operating states. 
This paper is organized as follows: the description of the operating principle of the SAPF and the conventional DPC control is presented in Section 2; Section 3 deals with the operation of the SAPF coupled to the PV system, based on the proposed DPC command in the presence of the FOPID voltage regulator and a fuzzy MPPT. Simulation results under different network voltage conditions_-balanced, unbalanced, and distorted — are presented in Section 4 and compared to the results of the other DPC strategies recently published. Finally, Section 5 provides a conclusion of this research.

\section{SAPFS CONTROLLED BY THE CONVENTIONAL DPC STRATEGY}

APFs, which are based on power electronics, have attracted the attention of researchers since the late 1970s. These devices are used to solve problems generated by nonlinear loads connected to power grids (Chaoui et al., 2010; Krama et al., 2017). The SAPFs are connected in a shunt between the power grid and the load; they inject harmonic currents into the power line with the same amplitude and opposite phase as the load's harmonic current. So, when the harmonics are introduced at the point of common coupling (PCC) of the line, the harmonic elimination of the load current is performed (Chaoui et al., 2010; Bengourina et al., 2018). For this reason, SAPFs are designed to obtain a power factor near unity and to achieve current harmonics and reactive power compensation consumed by the nonlinear loads (Aissa et al., 2018). The current source is sinusoidal because, at the output of the inverter, the delivery of the harmonic signals can compensate those existing on the electrical network (Chaoui et al., 2013; Aissa et al., 2018; Krama et al., 2017).

In the DPC approach, the active and the reactive powers replace the electromagnetic torque and the amplitude of the stator flux of the DTC method. It is known as a direct nonlinear control technique since it selects the appropriate voltage vector to be applied without the need for any modulation technique or coordinate transformation (Bengourina et al., 2018; Chaoui et al., 2010; Tareen et al., 2017). The basic concept of the DPC is to select the appropriate switching state from the switching table based on localization of the source voltage vector and errors. These errors are limited by a hysteresis band presented by active and reactive powers, as depicted in Figure 1.

The DC bus voltage is set to its desired value by a standard PI regulator (Bengourina et al., 2018).

The instantaneous apparent power $\left(\mathrm{S}_{\mathrm{s}}\right)$, the instantaneous active power $\left(\mathrm{P}_{\mathrm{s}}\right)$, and the instantaneous reactive power $\left(Q_{s}\right)$ for healthy three-phase electrical network are calculated using the expressions below (Chaoui et al., 2010; Krama et al., 2017):

$$
\begin{aligned}
& S_{s}=P_{s}+j Q_{s} \\
& P_{s}=V_{s a} I_{s a}+V_{s b} I_{s b}+V_{s c} I_{s c} \\
& Q_{s}=\frac{1}{\sqrt{3}}\left[\left(V_{s b}-V_{s c}\right) I_{s a}+\left(V_{s c}-V_{s a}\right) I_{s b}+\left(V_{s a}-V_{s b}\right) I_{s c}\right]
\end{aligned}
$$

where $\mathrm{V}_{\mathrm{sa}}, \mathrm{V}_{\mathrm{sb}}$ and $\mathrm{V}_{\mathrm{sc}}$ are healthy source voltages of the phase (a, b and c) and $\mathrm{I}_{\mathrm{sa}}, \mathrm{I}_{\mathrm{sb}}$ and $\mathrm{I}_{\mathrm{sc}}$ are the healthy source currents of the phase ( $a, b$ and $c)$. 


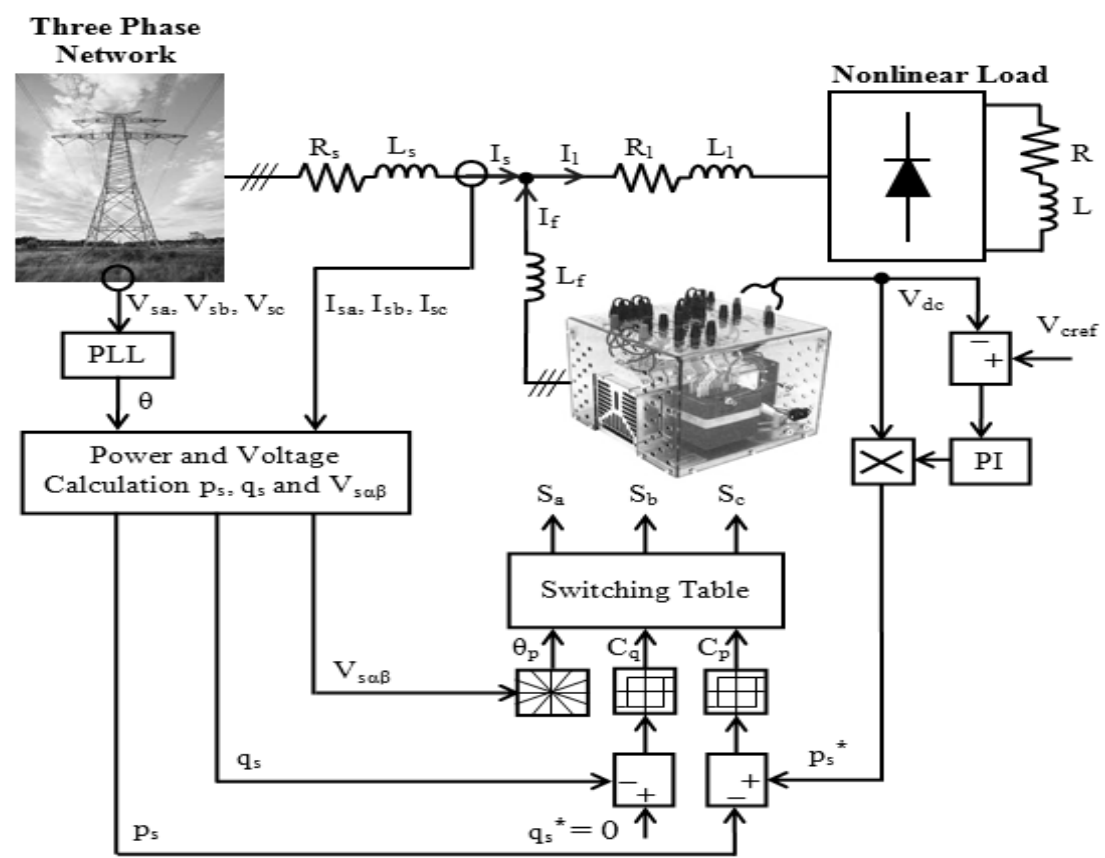

Figure 1. General structure of SAPF controlled by the DPC approach.

The reference reactive power is maintained at zero to ensure a unit power factor, whereas the reference active power is developed by multiplying the peak value of the current source generated by the DC bus voltage controller. Then, the powers are compared, and the obtained errors are applied to the hysteresis regulators (Bengourina et al., 2018).

The hysteresis regulators contain the errors of the instantaneous active and reactive powers with in the desired band. This method is based on two hysteresis regulators using as input the error signals between the reference values and the calculated active and reactive powers. The output of the controller switches between 0 and1. If the error is positive, the controller output is equal to 1 ; otherwise, it is 0 .

The influence of each control vector applied to the APF on the active and reactive powers is dependent on the exact localization of the source voltage vector. Thus, the switching table is built from the signals coming from the two outputs of the hysteresis comparators and the information on the localization of the source voltage vector.

According to the angle of the referenced source voltage vector to the $\alpha$-axis, the sector of the vector will be selected based on Figure 2. The angle $\theta_{p}$ is determined by an inverse trigonometric function, identified by the vector components $v_{s \alpha}$ and $v_{s \beta}$ of the voltage in the fixed reference space $(\alpha, \beta)$ :

$$
\theta_{p}=\tan ^{-1}\left(\frac{v_{s \beta}}{v_{s a}}\right)
$$

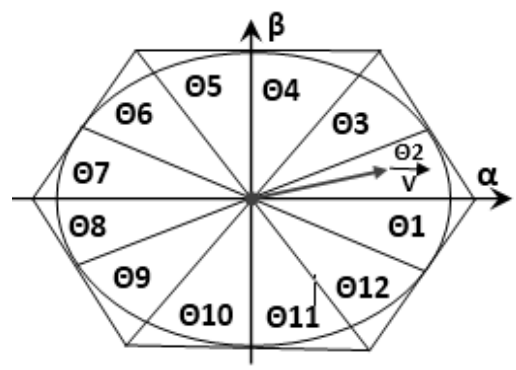

Figure 2. Sectors position on fixed coordinates. 
The switching table indicated in Table 1 is the principal component of DPC. It selects the appropriate voltage vector of the inverter to set the instantaneous active and reactive powers to the desired values (Chaoui et al., 2013; Aissa et al., 2018).

Table 1. Switching table presentation for the DPC strategy.

\begin{tabular}{|c|c|c|c|c|c|c|c|c|c|c|c|c|c|}
\hline $\boldsymbol{C}_{\boldsymbol{p}}$ & $\boldsymbol{C}_{\boldsymbol{q}}$ & $\boldsymbol{\theta}_{\mathbf{1}}$ & $\boldsymbol{\theta}_{\mathbf{2}}$ & $\boldsymbol{\theta}_{\mathbf{3}}$ & $\boldsymbol{\theta}_{\mathbf{4}}$ & $\boldsymbol{\theta}_{\mathbf{5}}$ & $\boldsymbol{\theta}_{\mathbf{6}}$ & $\boldsymbol{\theta}_{\mathbf{7}}$ & $\boldsymbol{\theta}_{\mathbf{8}}$ & $\boldsymbol{\theta}_{\mathbf{9}}$ & $\boldsymbol{\theta}_{\mathbf{1 0}}$ & $\boldsymbol{\theta}_{\mathbf{1 1}}$ & $\boldsymbol{\theta}_{\mathbf{1 2}}$ \\
\hline 1 & 1 & $v_{6}$ & $v_{7}$ & $v_{1}$ & $v_{0}$ & $v_{2}$ & $v_{7}$ & $v_{3}$ & $v_{0}$ & $v_{4}$ & $v_{7}$ & $v_{5}$ & $v_{0}$ \\
\hline 1 & 0 & $v_{7}$ & $v_{7}$ & $v_{0}$ & $v_{0}$ & $v_{7}$ & $v_{7}$ & $v_{0}$ & $v_{0}$ & $v_{7}$ & $v_{7}$ & $v_{0}$ & $v_{0}$ \\
\hline 0 & 1 & $v_{6}$ & $v_{1}$ & $v_{1}$ & $v_{2}$ & $v_{2}$ & $v_{3}$ & $v_{3}$ & $v_{4}$ & $v_{4}$ & $v_{5}$ & $v_{5}$ & $v_{6}$ \\
\hline 0 & 0 & $v_{1}$ & $v_{2}$ & $v_{2}$ & $v_{3}$ & $v_{3}$ & $v_{4}$ & $v_{4}$ & $v_{5}$ & $v_{5}$ & $v_{6}$ & $v_{6}$ & $v_{1}$ \\
\hline
\end{tabular}

\section{SOLAR SAPF CONTROLLED BY THE PROPOSED DPC STRATEGY Presentation of the proposed DPC strategy for the SAPF}

The proposed DPC for the SAPF is illustrated in Figure 3. This method is based on the principle of disturbance rejection. Its main role is to eliminate the effect of any network malfunctions due to unbalances and harmonics affecting the power supply in a PV system. The active and reactive powers generated by the harmonic component of the input currents are considered controlled variables. The proposed DPC strategy requires no active and reactive power perturbation reference to reject the influence of the distorted network (Chaoui et al., 2010; Bouafia et al., 2012). For this proposed command, the phase-locked loop (PLL) block is needed to extract the phase angle of the three-phase power supply. On the other hand, the PLL block participates in the determination of the three-reference input currents. The calculation of the active and reactive powers is performed between the errors recorded by the three input currents and their relative references in the presence of input voltages of healthy or deformed shapes. The stored errors between the imposed reference values and those of the calculated active and reactive powers are controlled by means of twolevel hysteresis controllers. By keeping the same technique for the conventional DPC, the appropriate switching states are selected through a lookup table based on the obtained errors and the position of the source voltage vector located in the fixed reference frame $(\alpha-\beta)$.

According to the schematic diagram in Figure 3, the three currents contributing to the calculation of active and reactive powers are defined as follows:

$$
\left[\begin{array}{l}
\varepsilon I_{s a} \\
\varepsilon I_{s b} \\
\varepsilon I_{s c}
\end{array}\right]=\left[\begin{array}{c}
I_{s a} \\
I_{s b} \\
I_{s c}
\end{array}\right]-\left[\begin{array}{c}
I_{s a}^{*} \\
I_{s b}^{*} \\
I_{s c}^{*}
\end{array}\right]
$$

In the proposed DPC, the amplitude of the input current $I_{\max }$ is determined by multiplying the signal from the output voltage controller FOPID by the measured voltage $V_{d c}$ and by a value gain $\frac{\sqrt{2}}{\sqrt{3} U}$. However, adequate sinusoidal form of these currents is ensured by the PLL block, as illustrated in Figure 3. Once these conditions are realized, the three reference source currents can be formulated easily as per

$$
\left[\begin{array}{l}
I_{s a}^{*} \\
I_{s b}^{*} \\
I_{s c}^{*}
\end{array}\right]=\left[\begin{array}{l}
I_{\max } \sin (w t) \\
I_{\max } \sin \left(w t-\frac{2 \pi}{3}\right) \\
I_{\max } \sin \left(w t+\frac{2 \pi}{3}\right)
\end{array}\right]
$$


After substituting equation (6) into equation (5), the following equation is obtained:

$$
\left[\begin{array}{l}
\varepsilon I_{s a} \\
\varepsilon I_{s b} \\
\varepsilon I_{s c}
\end{array}\right]=\left[\begin{array}{l}
I_{s a} \\
I_{s b} \\
I_{s c}
\end{array}\right]-\left[\begin{array}{l}
I_{\max } \sin (w t) \\
I_{\max } \sin \left(w t-\frac{2 \pi}{3}\right) \\
I_{\max } \sin \left(w t+\frac{2 \pi}{3}\right)
\end{array}\right]
$$

So, instantaneous active and reactive powers $\left(\mathrm{P}_{\mathrm{sc}}\right.$ and $\left.\mathrm{Q}_{\mathrm{sc}}\right)$ provided by the harmonic component are given by the following relations:

$$
\begin{aligned}
& P_{s c}=V_{s a} \varepsilon I_{s a}+V_{s b} \varepsilon I_{s b}+V_{s c} \varepsilon I_{s c} \\
& Q_{s c}=\frac{1}{\sqrt{3}}\left[\left(V_{s b}-V_{s c}\right) \varepsilon I_{s a}+\left(V_{s c}-V_{s a}\right) \varepsilon I_{s b}+\left(V_{s a}-V_{s b}\right) \varepsilon I_{s c}\right]
\end{aligned}
$$

In this situation, $\mathrm{V}_{\mathrm{sa}}, \mathrm{V}_{\mathrm{sb}}$ and $\mathrm{V}_{\mathrm{sc}}$ represent the unbalanced or distorted source voltages of the phase ( $\mathrm{a}, \mathrm{b}$ and $\mathrm{c}$ ).

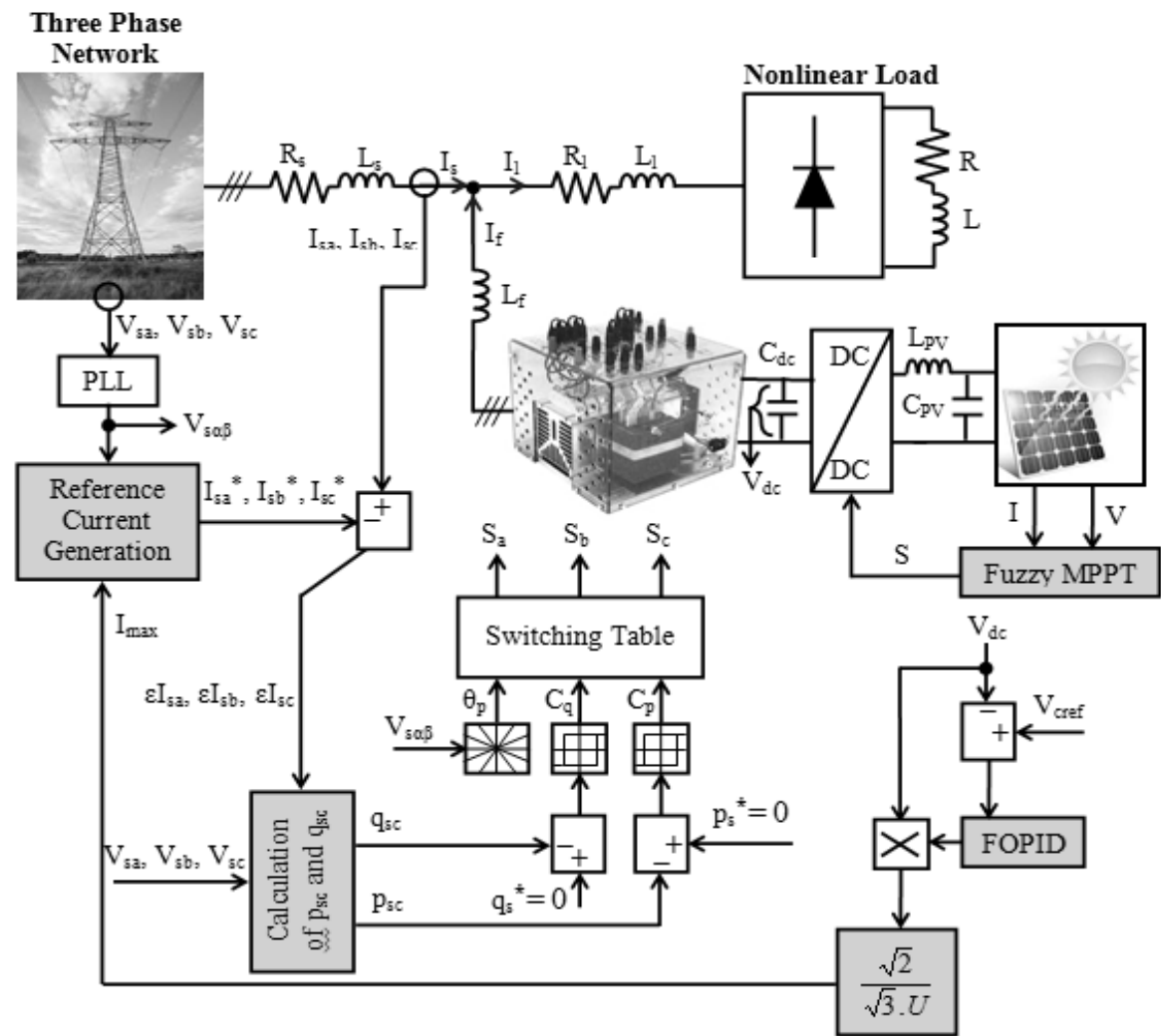

Figure 3. General structure of a SAPF controlled by the proposed DPC approach in the PV system.

To reject disturbances affecting the power supply, the reference active and reference reactive powers can be set to zero, so that source currents follow their references. The observed error for this situation is zero, generating a calculated active and reactive power equal to zero, regardless of the type of the input voltage source.

\section{FOPID DC bus controller}

Controlling the DC bus voltage of the solar APF is the key to the achieving of the target the quality of energy under variable conditions. The conventional PI controller suffers from some weaknesses in the dynamic state. To address 
this issue, the proposed control is equipped with a new regulator, namely, the FOPID, which replaces the standard PI regulator to maintain the DC bus voltage at its desired value under varying reference, load and weather conditions affecting the PV system.

The FOPID controller, denoted $\mathrm{FOPI}^{\varepsilon} \mathrm{D}^{\eta}$, has the general form, in which the integral $\varepsilon$ and the derivative $\eta$ are orders of the actions, not integers (Sondhi et al., 2014). Owing to their better dynamic response and performance, FOPID controllers have become the dominating trend in industrial controllers, attracting the attention of researchers in various fields, such as aerospace control systems (Gorripotu et al., 2015), hypersonic flight vehicle and automatic voltage regulation (Sondhi et al., 2014). The main advantage of the FOPID controller lies in the addition of two adjustable parameters $(\varepsilon, \eta)$, which offer more flexibility and low sensitivity to any variations in the system parameters (Gorripotu et al., 2015). Additionally, it provides suitable convergence and conservation of the adjusted variable to its desired value, as shown in Figure 4.

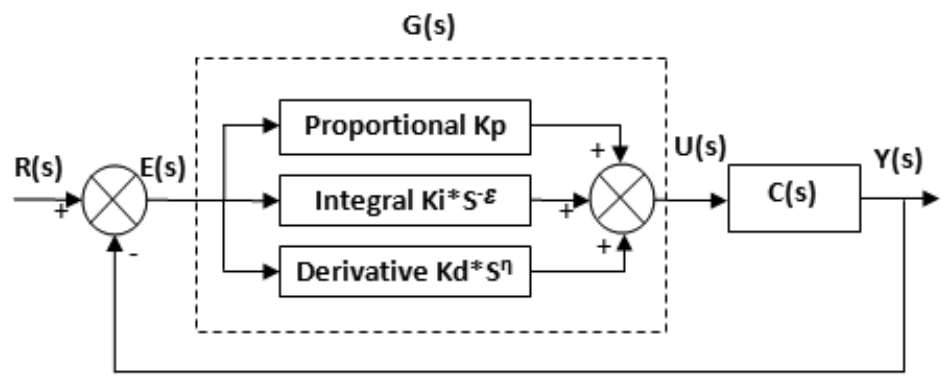

Figure 4. FOPID controller structure.

From Figure 4, the transfer function $G(s)$ of the FOPID controller is defined by the following expression:

$$
G(s)=\frac{U(s)}{E(s)}=K_{p}+K_{i} s^{-\varepsilon}+K_{d} s^{\eta}
$$

where $K_{p}, K_{i}, K_{d}$ are the proportional, integral, and derivative gain factors, respectively; $\varepsilon$ and $\eta$ are the integral and the derivative order, respectively; $R(s)$ is the input signal; $E(s)$ represents the error signal; and $Y(s)$ is the output signal.

Concerning the design of the FOPID regulator in this paper, the first step is to calculate the three parameters of the FOPID regulator $\left(K_{p}, K_{i}\right.$ and $\left.K_{d}\right)$ by the Ziegler and Nichols method when $\varepsilon=\eta=1$, which is equivalent to the parameter adjustment of a simple standard PID regulator. The second step is to adjust the two parameters $\varepsilon$ and $\eta$, minimising a performance criterion $J$ represented by the integral of the square of the error, calculated by the Hall and Sartorius method as shown by the following equations (Altas et al., 2008):

$$
\begin{aligned}
& J=\int_{0}^{\infty}[e(t)]^{2} d t=\int_{0}^{\infty}[r(t)-y(t)]^{2} d t \\
& J(\varepsilon, \eta)=\frac{1}{2 \pi j} \int_{-\infty}^{+\infty} E(s) E(-s) d s
\end{aligned}
$$

Once the five parameters $\left(K_{p}, K_{i}, K_{d}, \varepsilon\right.$ and $\left.\eta\right)$ are known, the proposed FOPID regulator will be easily identified by using equation (10) and improved by trial and error. It should be noted that the fractional operators characterizing the developed FOPID are difficult to program for use in simulation and practical validation. The resolution of this problem requires the Oustaloup approximation. 


\section{Approximation method of fractional order operators}

Oustaloup et al. (2000) proposed a convenient method to approximate the fractional order (FO) to Laplace transfer functions (TFs). The term $s^{\alpha}$ is the Oustaloup's approximation model (Oustaloup et al., 1995), $s$ is the Laplace transform variable, and $\alpha$ is a real number between -1 and $1 . s^{\alpha}$ is designated as an FO differentiator if $(0<\alpha<1)$ and an FO integrator if $(-1<\alpha<0)$. This method, called recursive Oustaloup's filter, is distributed in a limited frequency band $\left[\omega_{b} \omega_{h}\right]$. The Oustaloup approximation is carried out on the basis of the following relations

(Oustaloup et al., 1995; Rayalla et al., 2019):

$$
s^{\alpha}=K \prod_{k=-N}^{N} \frac{s+\omega_{k}^{\prime}}{s+\omega_{k}}
$$

for the frequency range $\left(\omega_{b}, \omega_{h}\right)$,

$$
\begin{aligned}
& \omega_{k}^{\prime}=\omega_{b}\left(\frac{\omega_{h}}{\omega_{b}}\right)^{\left(\frac{k+N+0.5(1-\alpha)}{2 N+1}\right)} \\
& \omega_{k}=\omega_{b}\left(\frac{\omega_{h}}{\omega_{b}}\right)^{\left(\frac{k+N+0.5(1+\alpha)}{2 N+1}\right)} \\
& K=\omega_{h}^{\alpha}
\end{aligned}
$$

where $\omega_{k}^{\prime}$ and $\omega_{k}$ are the zeros and the poles of interval $k$, respectively; $\mathrm{K}$ represents the adjustment gain; $\omega_{b}$ and $\omega_{h}$ are the low and the high frequencies, respectively; $N$ is the number of poles and zeros; and $(2 N+1)$ is the approximation function order.

\section{Advanced MPPT controller}

Fuzzy logic belongs to the family of artificial intelligence techniques that imitate human reasoning. The fundamental principles of this theory were pioneered by the researcher Zadeh (1965). This method is used in our research for the MPPT of a PV module under any weather conditions because it does not require knowledge of the mathematical models of linear and nonlinear controlled systems (Altin et al., 2013; Algazar et al., 2012).

Generally, the fuzzy logic controller (FLC) comprises three essential blocks: fuzzification, rules of inference and defuzzification (Boukezata et al., 2016; Altas et al., 2008). The fuzzification step is the process of changing the digital input variables into linguistic variables using membership functions. The rules-of-inference step gives the output of the fuzzy logic controller by the Mamdani method with a max-min technique depending on the set belonging to the rule base. The defuzzification step converts the linguistic variables into a crisp value, which determines the duty cycle increment $\Delta D$.

The fuzzy MPPT values are represented by an error $E$ and a variation in error $\Delta E$ as the inputs. The error and its variation are given by the following equations (Algazar et al., 2012):

$$
\begin{aligned}
& E(K)=\frac{P(K)-P(K-1)}{V(K)-V(K-1)} \\
& \Delta E=E(K)-E(K-1)
\end{aligned}
$$


where $P(k), P(k-1), V(k)$ and $V(k-1)$ are the power and the voltage of the PV for two sampling times $k$ and $(k-1)$, respectively.

The proposed algorithm has two input variables: $\Delta P(k)$ and $\Delta V(k)$. The output variable is the duty cycle $\Delta D(k)$. The variables $\Delta P(k)$ and $\Delta V(k)$ are given by the following equations (Algazar et al., 2012; Boukezataet al., 2016):

$$
\begin{aligned}
& \Delta P(K)=P(K)-P(K-1) \\
& \Delta V(K)=V(K)-V(K-1)
\end{aligned}
$$

where, at the MPP of the PV array, $\Delta P(k)$ and $\Delta V(k)$ are null.

The basic rules for the fuzzy MPPT algorithm is based on the two input variables $(\Delta \mathrm{P}(\mathrm{k}), \Delta \mathrm{V}(\mathrm{k}))$ and on the output variable $(\Delta \mathrm{D})$. The $\Delta \mathrm{P}(\mathrm{k})$ and $\Delta \mathrm{V}(\mathrm{k})$ are divided into five fuzzy sets denoted as: Negative Big (NB), Negative Small (NS), Zero (Z), Positive Small (PS) and Positive Big (PB). The rule base connects the fuzzy inputs to the fuzzy output by the master rule of syntax: " If: A is ... and B is ..., Then: $\mathrm{C}$ is ...". According to Table 2 (Algazar et al., 2012; Boukezata et al., 2016), grouping all the possible relations between the inputs and the output of the developed controller, we can give the following example: If: $\Delta \mathrm{P}$ is $\mathrm{PB}$ and $\Delta \mathrm{V}$ is NB Then: $\Delta \mathrm{D}$ is NS.

The choice of the membership functions form of the proposed controller is of the triangular type. The center of gravity method for defuzzification step is used to calculate the incremental duty cycle $\Delta \mathrm{D}$ (Boukezata et al., 2016; Ouchen et al., 2016; Benlahbib et al., 2018):

$$
\Delta D=\frac{\sum_{j=0}^{n} w_{j} \Delta D_{j}}{\sum_{j=0}^{n} w_{j}}
$$

Table 2 Decision table.

\begin{tabular}{|c|c|c|c|c|c|}
\hline $\mathbf{\Delta P} \backslash \mathbf{\Delta} \mathbf{V}$ & $\mathbf{N B}$ & NS & $\mathbf{Z}$ & PS & PB \\
\hline $\mathbf{N B}$ & PS & PB & PB & NB & NS \\
\hline $\mathbf{N S}$ & $\mathrm{Z}$ & PS & PS & NS & Z \\
\hline $\mathbf{Z}$ & $\mathrm{Z}$ & $\mathrm{Z}$ & $\mathrm{Z}$ & $\mathrm{Z}$ & $\mathrm{Z}$ \\
\hline $\mathbf{P S}$ & $\mathrm{Z}$ & NS & NS & PS & $\mathrm{Z}$ \\
\hline PB & NS & NB & NB & PB & PS \\
\hline
\end{tabular}

With $\mathrm{n}$ is the maximum number of effective rules, $\mathrm{w}$ represents the weighting factor and $\Delta \mathrm{D}_{\mathrm{j}}$ is the value corresponding to $\Delta \mathrm{D}$.

Finally, the duty cycle is obtained by adding this change to the previous value of the control duty cycle as mentioned in the following equation (Boukezata et al., 2016; Ouchen et al., 2016; Benlahbib et al., 2018):

$$
D(K+1)=D(K)+\Delta D(K)
$$




\section{PRESENTATION AND DISCUSSION OF SIMULATION RESULTS}

Various simulations were performed using MATLAB/Simulink to evaluate the proposed approaches. The parameters used for these tests are shown in Table 3.

Table 3. Simulation parameters.

\begin{tabular}{|c|c|}
\hline Parameters & Values with dimensions \\
\hline $\mathrm{V}_{\mathrm{s}}, \mathrm{F}_{\mathrm{s}}$ & $70 \mathrm{~V}, 50 \mathrm{~Hz}$ \\
\hline $\mathrm{F}_{\text {switching }}(\mathrm{DC} / \mathrm{AC}$ APF converter $)$ & $20 \mathrm{KHz}$ \\
\hline $\mathrm{L}_{\mathrm{s}}, \mathrm{R}_{\mathrm{s}}$ & $0.1 \mathrm{mH}, 0.1 \Omega$ \\
\hline $\mathrm{L}_{\mathrm{l}}, \mathrm{R}_{\mathrm{l}}$ & $0.566 \mathrm{mH}, 0.01 \Omega$ \\
\hline $\mathrm{L}_{\mathrm{f}}, \mathrm{R}_{\mathrm{f}}, \mathrm{C}_{\mathrm{dc}}$ & $2.5 \mathrm{mH}, 0.01 \Omega, 2200 \mu \mathrm{F}$ \\
\hline $\mathrm{L}_{\mathrm{g}} \mathrm{R}$ & $10 \mathrm{mH}, 40 \Omega$ \\
\hline $\mathrm{C}_{\mathrm{pv}}, \mathrm{L}_{\mathrm{pv}}$ & $20 \mu \mathrm{F}, 3 \mathrm{mH}$ \\
\hline $\mathrm{NC}$ bus voltage reference $\left(\mathrm{V}_{\text {cref }}\right)$ & $226 \mathrm{~V}$ \\
\hline $\mathrm{F}_{\text {switching }}(\mathrm{DC} / \mathrm{DC}$ boost converter $)$ & $5 \mathrm{kHz}$ \\
\hline $\mathrm{N}, \omega_{\mathrm{b}}, \omega_{\mathrm{h}}$ & $2,10^{-2} \mathrm{rad} / \mathrm{s}, 10^{2} \mathrm{rad} / \mathrm{s}$ \\
\hline $\mathrm{Kp}, \mathrm{Kd}, \mathrm{Ki}$ & $0.3,0.3,3$ \\
\hline $\mathcal{E}, \eta$ & $0.1,0.1$ \\
\hline
\end{tabular}

The simulation results of the two cases, (1) SAPF controlled by the conventional DPC, equipped with conventional PI and fuzzy MPPT, and (2) the solar SAPF controlled by the proposed DPC, equipped with a FOPID regulator and a fuzzy MPPT, operating under a balanced feed power supply, are shown in Figures 5, 6, 8 and 9. Figures 5 and 6 show the waveforms of the voltages $V_{s}$ and source currents $I_{s}$, the filter currents $I_{f}$ and charge currents $I_{l}$ together with their respective zooms. The filtering device was operated under different conditions to assess its effectiveness. After applying the SAPF at time $t=0.1 \mathrm{~s}$, the source currents became sinusoidal and in phase with their corresponding source voltages. At instant $t=0.4 \mathrm{~s}$, the solar APF starts operating. During the time interval [0.4-2] s, the source currents remain sinusoidal and in phase opposition with the corresponding voltages despite irradiation $(G)$ changes. The filter currents and load currents ensure the proper functioning of the studied filter since they react positively to the changes. 

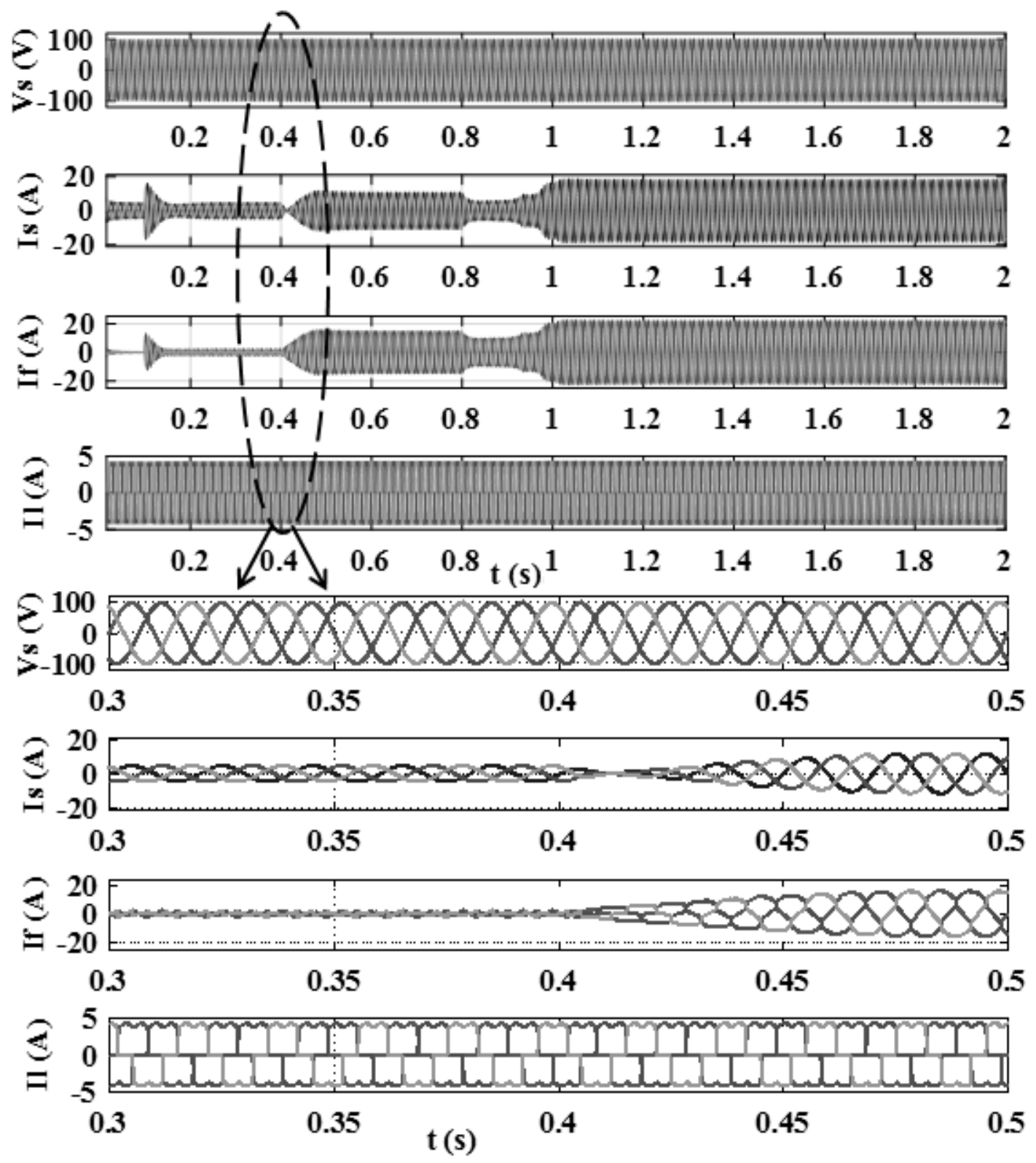

Figure 5. Simulation results of the solar FAP based on conventional DPC equipped with the classical PI regulator and fuzzy MPPT controller (source voltages and currents, filter and load currents). 


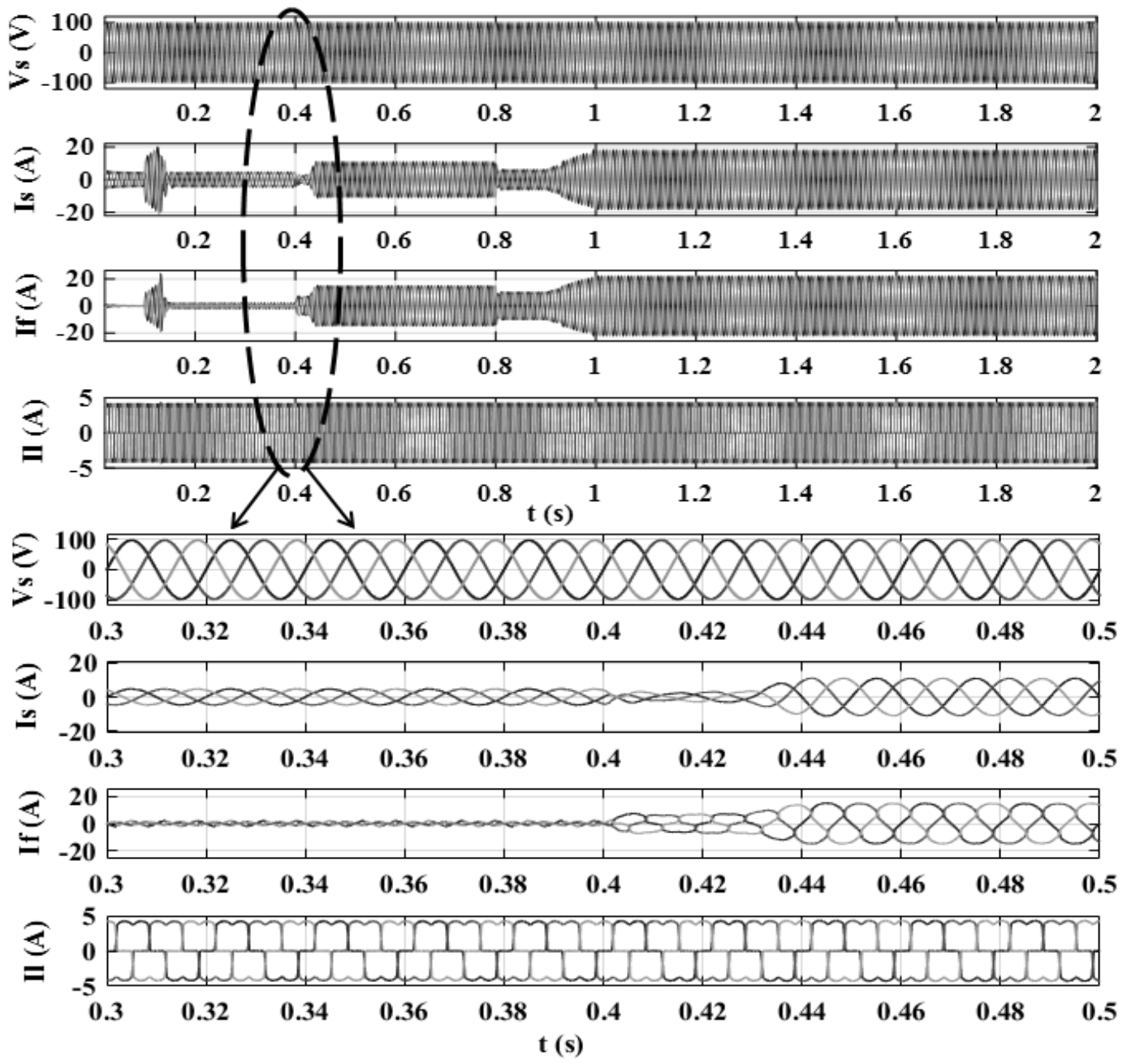

Figure 6. Simulation results of the solar FAP based on the proposed DPC equipped with the FOPID regulator and fuzzy MPPT controller (source voltages and currents, filter and load currents).

Figure 7 shows the current $I$ and the power $P_{p v}$ of the PV generator under different solar irradiation profiles. With zero irradiation, no current or power is generated before time $t=0.4 \mathrm{~s}$. From 0.4 to $2 \mathrm{~s}$, the current and the power of the PV accurately follow their imposed trajectories by the applied irradiation profile. When the irradiation increases from 0 to $600 \mathrm{~W} / \mathrm{m}^{2}$, the $3000 \mathrm{~W}$ MPP is reached with a current of 25 A thanks to the fuzzy MPPT algorithm. At time $t=0.8 \mathrm{~s}$, the irradiation decreases from 600 to $400 \mathrm{~W} / \mathrm{m}^{2}$, followed by a decrease in power from 3000 to $1990 \mathrm{~W}$ and current from 25 to $15 \mathrm{~A}$. Finally, in the time interval [0.9-2] s, solar irradiation increases from 400 to $1000 \mathrm{~W} / \mathrm{m}^{2}$, and the power and the maximum current recorded are $5000 \mathrm{~W}$ and $40 \mathrm{~A}$, respectively. The solar irradiation profile of the PV system with its obtained currents and powers was applied to our solar APF under different control strategies. 

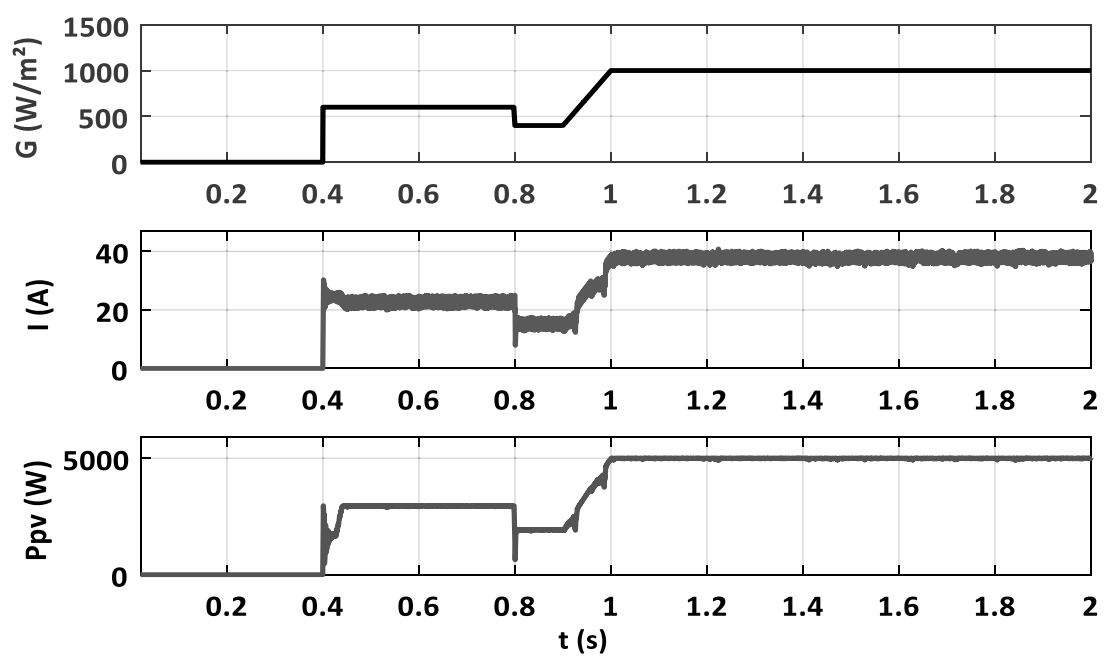

Figure 7. Irradiation profile, current and power of the PV array.

Figures 8 and 9 show powers and DC bus voltage evolution for the two cases. When irradiation $G$ is zero, the network supplies all the power $P_{s}$ to the load $P_{l}$. After injection, in the time interval of $0.4-2 \mathrm{~s}$, the PV generator supplies the power demanded $P_{f}$ by the nonlinear load and transfers the remaining power to the network.

During the time interval [0.1-2] s, the reactive power of the network $Q_{s}$ becomes zero after the insertion of the $\mathrm{SAPF}$, and the reactive power demanded by the load $Q_{l}$ is ensured by the same filter $Q_{f}$. By contrast, prior to filtering, the grid provides reactive power to the nonlinear load.
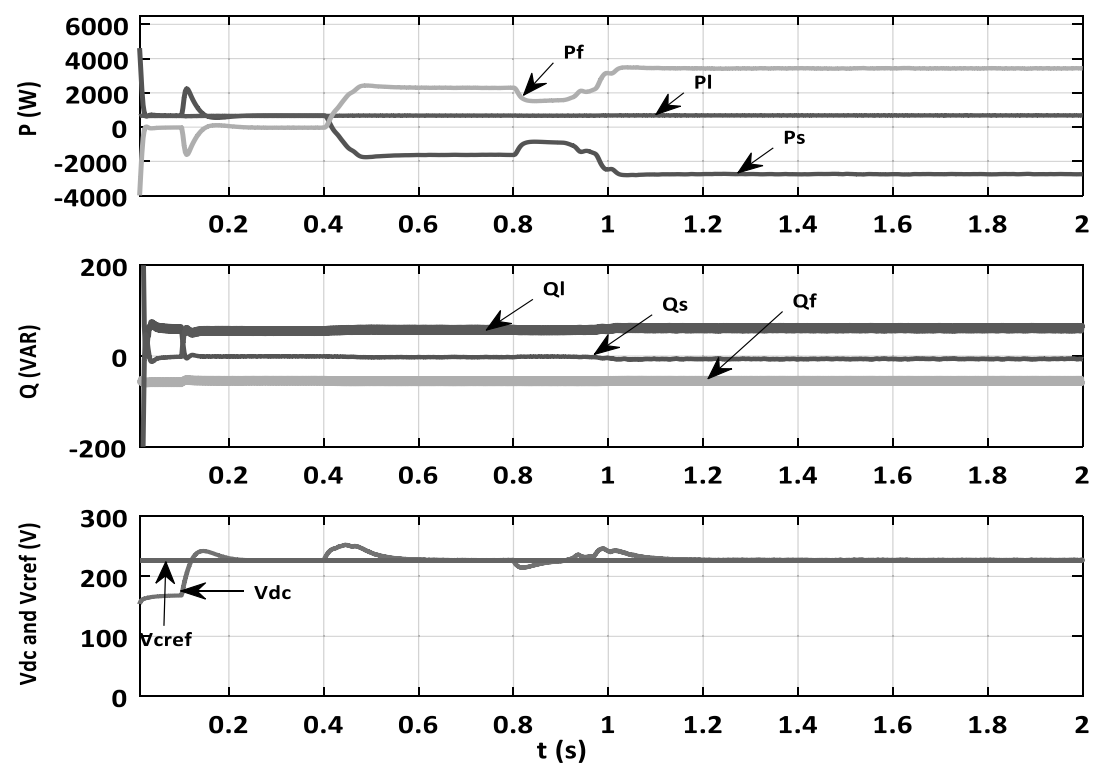

Figure 8. Powers and DC bus voltage evolution for the conventional DPC equipped with the classic PI regulator and fuzzy MPPT controller for the studied solar APF.

For the proposed DPC command, indicated in Figure9, it should be noted that the two calculated active $P_{s c}$ and reactive $Q_{s c}$ powers are null. They correspond to their references as required.

On the other hand, the DC bus voltage $V_{d c}$ stabilizes at its desired value during the insertion of SAPF and then returns to its reference $V_{\text {cref }}$ at each irradiation variation justified by the power exchange between the grid, the nonlinear load 
and the active power filter, as shown in Figures 8 and 9. Moreover, in the transient state, when applying the irradiation profile of Figure 7, the voltage $V_{d c}$ controlled by the FOPID regulator clearly exhibits good response compared to that regulated by the conventional PI.
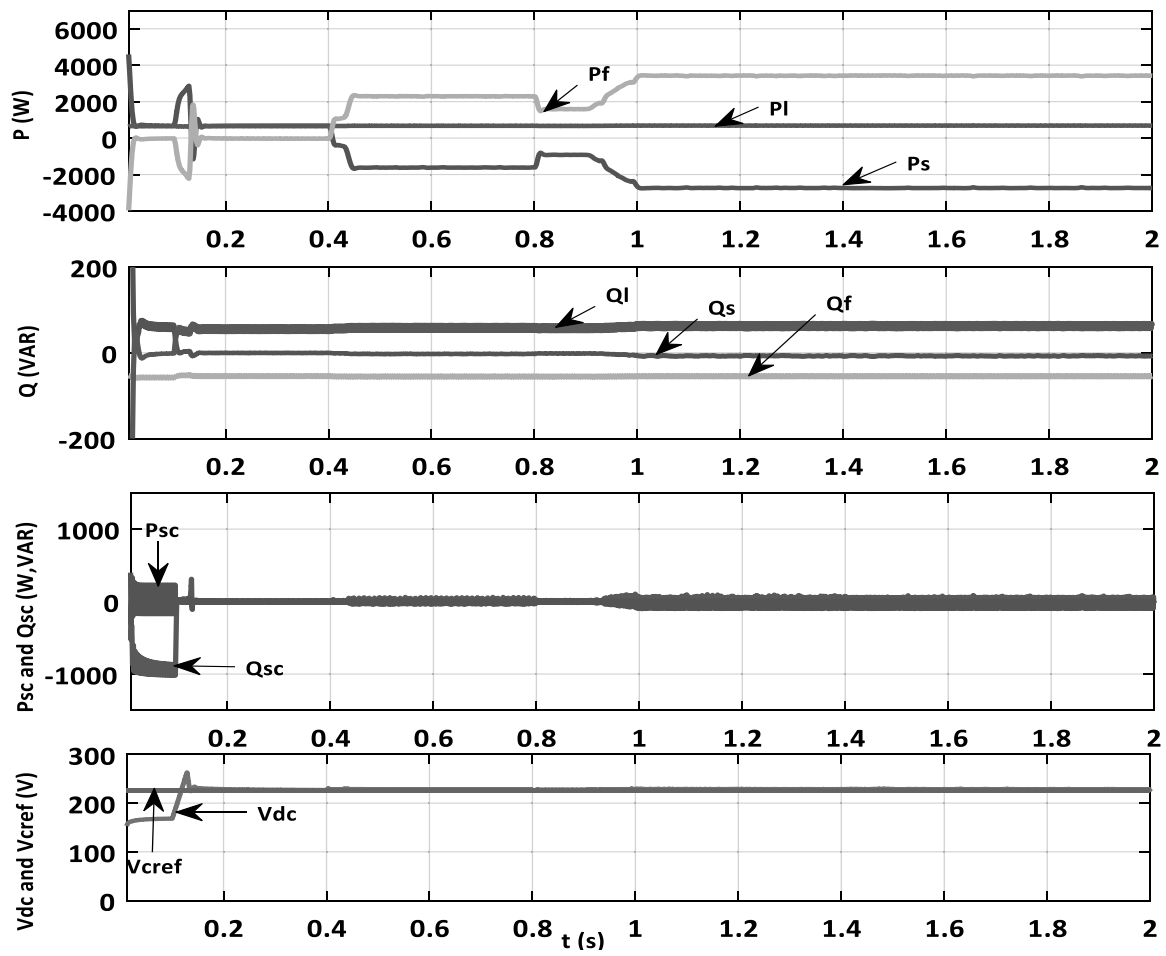

Figure 9. Powers and DC bus voltage evolution for the proposed DPC equipped with the FOPID regulator and fuzzy MPPT controller for the studied solar APF.

Table 4. Comparative study of the proposed FOPID with conventional PI controller before and after introducing advanced MPPT controller for the solar APF.

\begin{tabular}{|c|c|c|c|c|}
\hline & \multicolumn{4}{|c|}{ Recorded values in transient state for the dc bus voltage } \\
\hline & $\begin{array}{c}\text { SAPF without PV } \\
\Delta \mathrm{V}(\mathrm{V})\end{array}$ & $\begin{array}{c}\text { SAPF without PV } \\
\Delta \mathrm{t}(\mathrm{s})\end{array}$ & $\begin{array}{c}\text { SAPF with PV } \\
\Delta V(V)\end{array}$ & $\begin{array}{c}\text { SAPF with PV } \\
\Delta \mathrm{t}(\mathrm{s})\end{array}$ \\
\hline \multirow{2}{*}{$\begin{array}{l}\text { Proposed DPC with } \\
\text { FOPID regulator }\end{array}$} & Overshoot of 36 & 0.0163 & \multirow{2}{*}{ Overshoot of 3.6} & \multirow{2}{*}{0.0101} \\
\hline & Overshoot of 7.63 & 0.01189 & & \\
\hline \multirow{4}{*}{$\begin{array}{l}\text { Conventional DPC } \\
\text { with standard PI } \\
\text { regulator }\end{array}$} & \multirow{4}{*}{ Overshoot of 15.75} & \multirow{4}{*}{0.119} & Overshoot of 21.15 & 0.2245 \\
\hline & & & Voltage drop of 12.63 & 0.108 \\
\hline & & & Overshoot of 11.87 & 0.075 \\
\hline & & & Overshoot of 19.82 & 0.216 \\
\hline
\end{tabular}

Table 4 compares the proposed FOPID with a conventional PI controller before and after introducing the advanced MPPT controller for the solar APF. The proposed FOPID controller presents lower and fewer overshoots, which last for a short time during irradiation changes.

Before filtering and at $\mathrm{G}=0 \mathrm{~W} / \mathrm{m}^{2}$ between 0 and $0.1 \mathrm{~s}$, the form of the source current is distorted and rich in harmonics generated by nonlinear load; the value of current harmonics distortion is $30.35 \%$. However, the source current becomes sinusoidal and in phase with its network voltage after the insertion of SAPF at the instant $\mathrm{t}=0.1 \mathrm{~s}$ and 
the THD of this current is $1.59 \%$. From 0.4 to 2 s, the SAPF mode interfaces with the PV system; the source current remains sinusoidal and in the opposite phase with the corresponding voltages despite the change in irradiation. The total harmonic distortion in this situation is $0.88 \%$, in accordance with the IEEE-519 standard. It should be noted that the THD of the conventional DPC control for the solar FAP is $2.49 \%$ (FAP without PV) and 1\% (FAP with PV).

\section{Distorted and unbalanced grid voltages tests}

The first test of the robustness of the DPC strategy control is based on the distortion of the grid voltage. In this test, the fifth voltage harmonic is injected on the fundamental of input voltages.

In the absence of the FAP, the two studied control strategies present a nonsinusoidal source current with a THD of $28.77 \%$. The obtained simulation results for the solar APF governed by the proposed DPC with the FOPID regulator show a sinusoidal source current under a distorted source voltage, as illustrated in Figure 11.

The measured THDs for the source currents of Figure 11 (FAP without PV) and (FAP with PV) are 3.04\% and 3.25\%, respectively. However, by using conventional DPC with a standard PI for the same filter and maintaining the same operating conditions a strongly deteriorated source current is present, as illustrated in Figure 10. The measured THDs for these source currents (FAP without PV) and (FAP with PV) are $11.81 \%$ and $12.65 \%$ respectively. As can be clearly seen from comparing THD values for the treated controls, the proposed DPC is better than the conventional DPC.
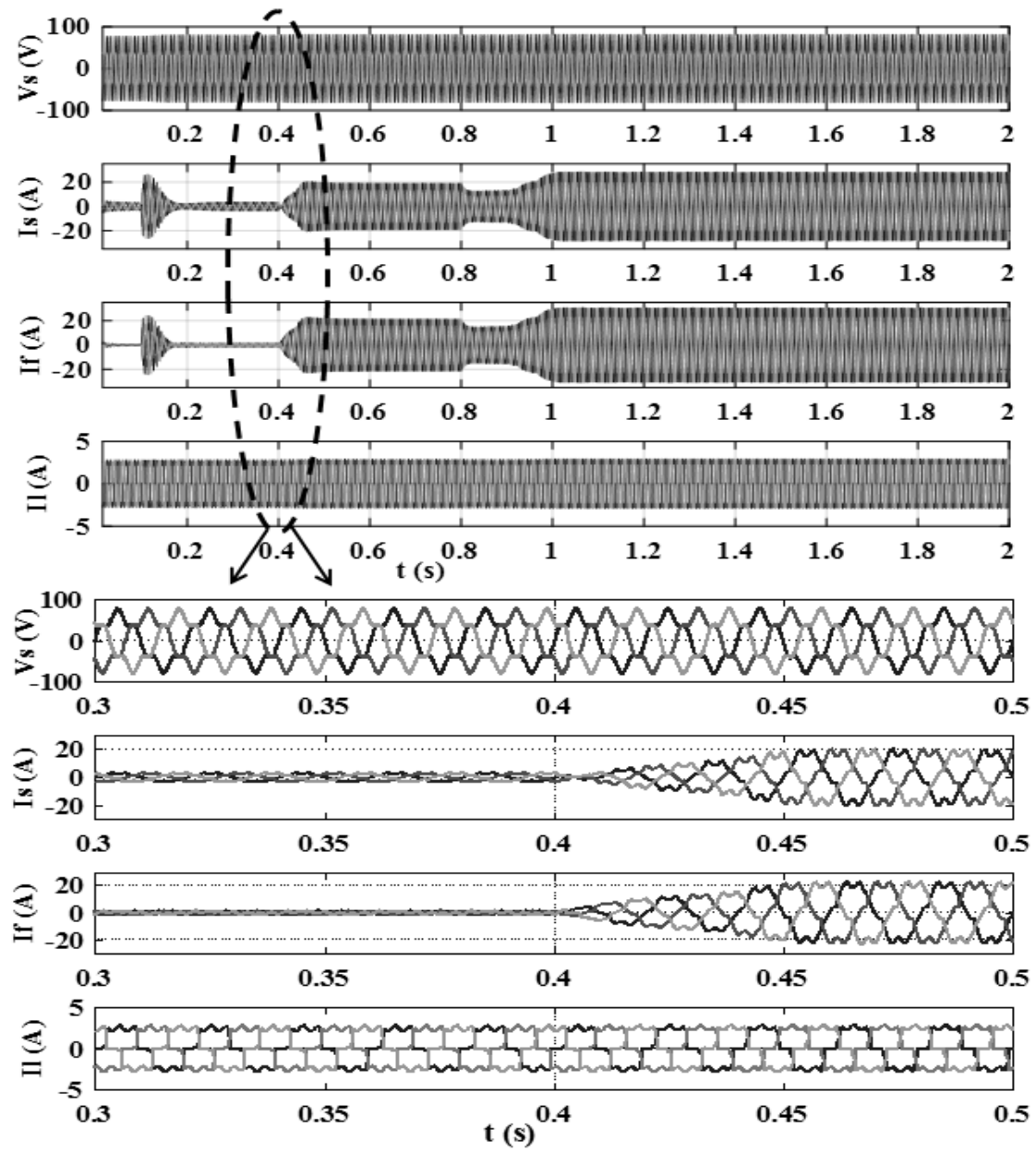

Figure 10. Simulation results of the solar FAP based on conventional DPC equipped with the classical PI regulator and fuzzy MPPT controller under distorted grid voltages (source voltages and currents, filter and load currents). 

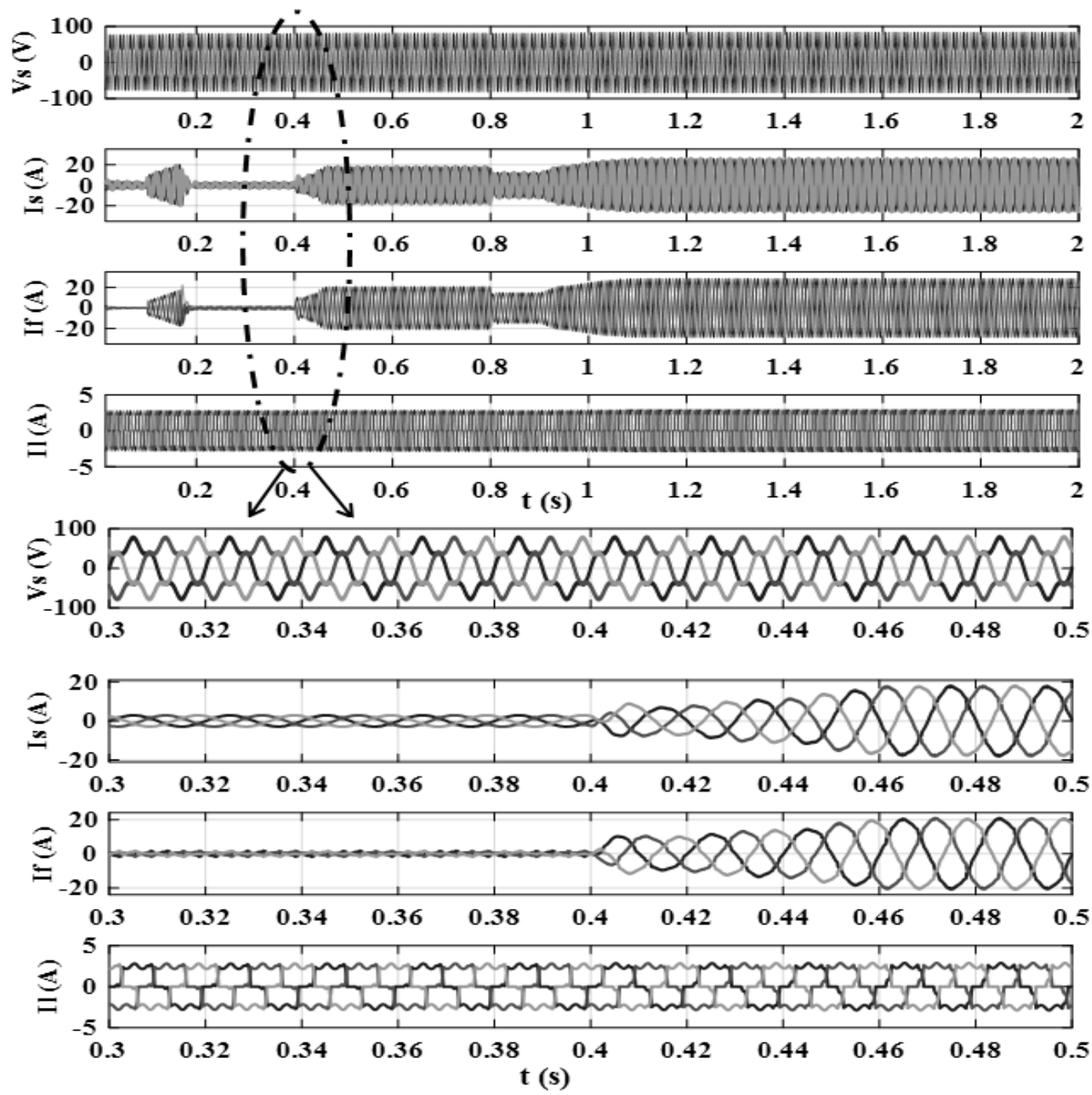

Figure 11. Simulation results of the solar FAP based on proposed DPC equipped with the FOPID regulator and fuzzy MPPT controller under distorted grid voltages (source voltages and currents, filter and load currents).

The second robustness test of the DPC control strategy is based on the nonbalancing of the three input voltages: $V_{s a}=75 \mathrm{~V}, V_{s b}=90 \mathrm{~V}$ and $V_{s c}=65 \mathrm{~V}$. These results confirm the robustness and superiority of the proposed DPC with the FOPID controller for solar filter operation in the unbalanced mode of source voltages. Figures 13 presents that the input currents are balanced and represent sinusoidal waveforms with recorded THDs of $2.93 \%$ (FAP without PV) and 2.95\% (FAP with PV). 

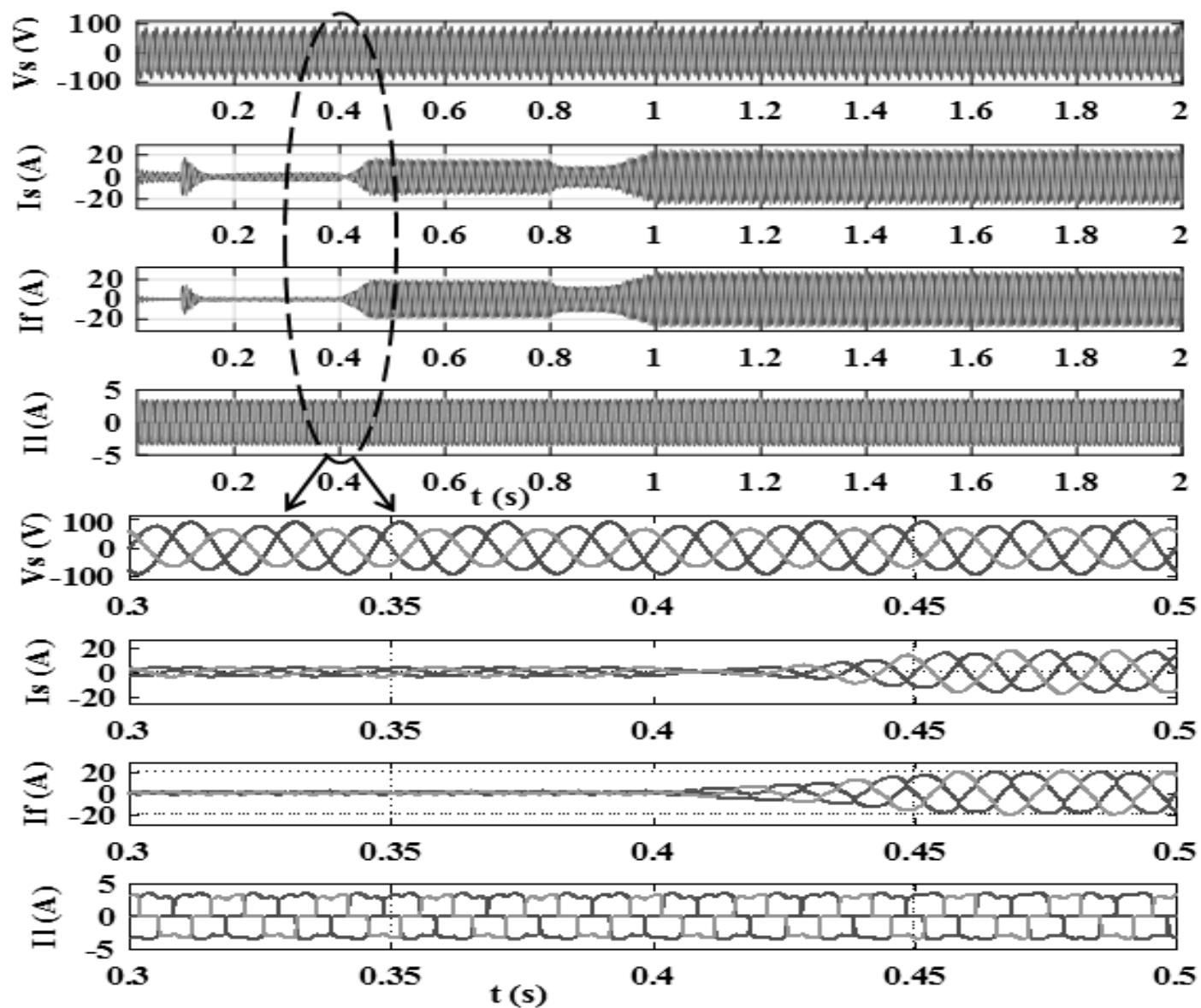

Figure 12. Simulation results of the solar FAP based on conventional DPC equipped with the classical PI regulator and fuzzy MPPT controller under unbalanced grid voltages (source voltages and currents, filter and load currents).

In the case of the conventional DPC with standard PI for the same filter (Figure12), while maintaining the same operating conditions, the obtained source currents are deformed and degraded, which is justified by the high THD values of $5.74 \%$ (FAP without PV) and 5.10\% (FAP with PV). In the absence of the FAP, the two control strategies simulated under an unbalanced power grid operation have a nonsinusoidal source current with THD being equal to $36.90 \%$. 


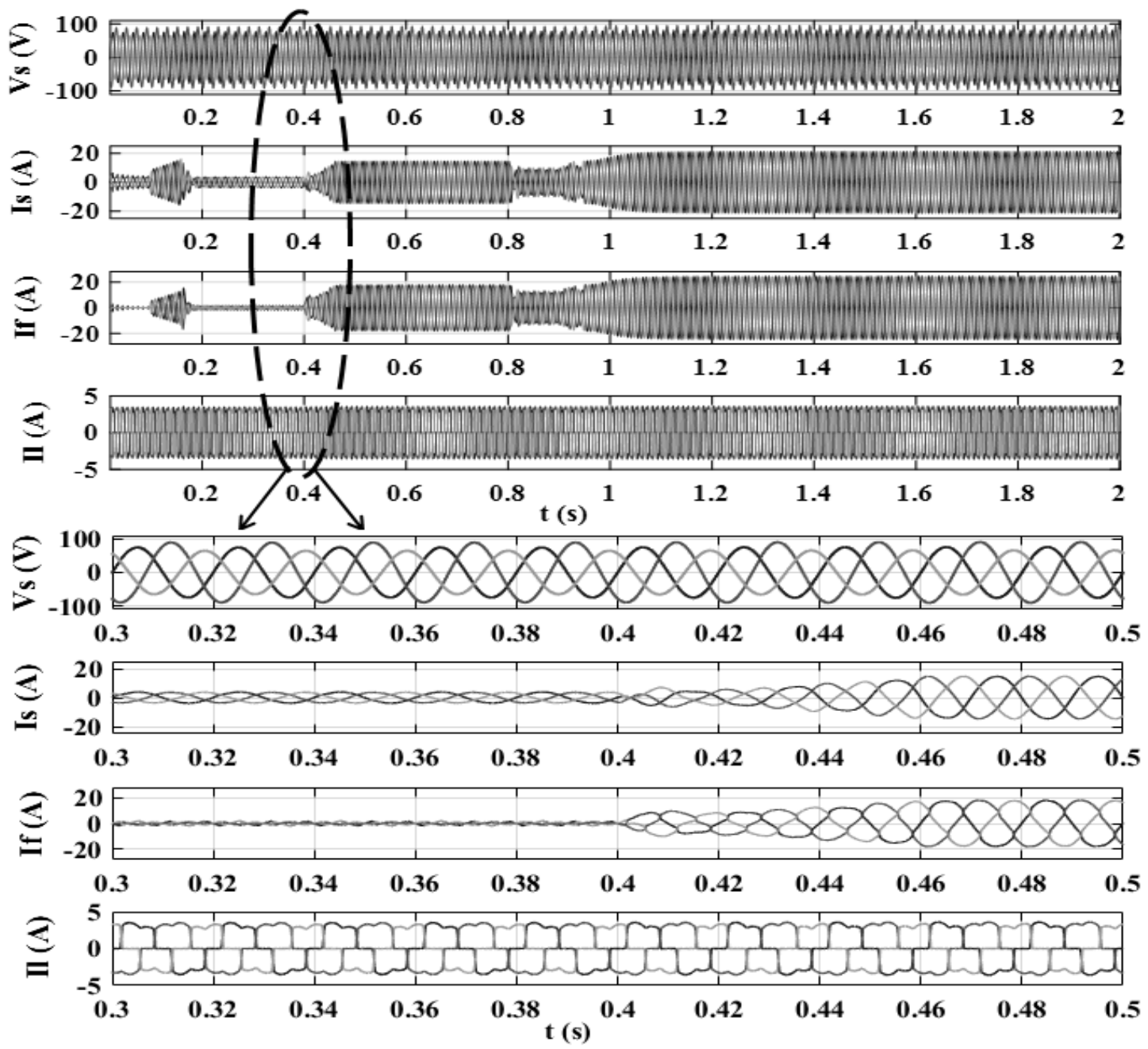

Figure 13. Simulation results of the solar FAP based on the proposed DPC equipped with the FOPID regulator and fuzzy MPPT controller under unbalanced grid voltages (source voltages and currents, filter and load currents).

The simulation results characterizing the total harmonic distortion of the source currents for the studied strategies are summarized in Table 5. The proposed DPC with the FOPID controller outperforms the other investigated strategies and to those recently published regarding the operation of the solar APFs in the case of equilibrium of the power supply. In unbalanced or distorted mode, the solar APF also offers acceptable results. 
Table 5. Comparative analysis in terms of THD levels of source current.

\begin{tabular}{|c|c|c|c|}
\hline \multirow{2}{*}{ Employed Control } & \multicolumn{2}{|c|}{ THD of source current (\%) } \\
\cline { 2 - 4 } & Without SAPF & SAPF without PV & SAPF with PV \\
\hline $\begin{array}{c}\text { Conventional DPC with classical PI controller } \\
\text { under balanced grid voltage }\end{array}$ & 30.35 & 02.49 & 01.00 \\
\hline $\begin{array}{c}\text { Proposed DPC with FOPID controller under } \\
\text { balanced grid voltage }\end{array}$ & 30.35 & 01.59 & 00.88 \\
\hline $\begin{array}{c}\text { Reference: (Boukezata et al., 2016) } \\
\text { Reference: (Krama et al., 2017) }\end{array}$ & Not mentioned & 01.24 & 01.34 \\
\hline $\begin{array}{c}\text { Reference: (Bengourina et al., 2018) } \\
\text { Conventional DPC with classical PI controller } \\
\text { under distorted grid voltages }\end{array}$ & 23.15 & Not mentioned & 02.20 \\
\hline $\begin{array}{c}\text { Proposed DPC with FOPID controller under } \\
\text { distorted grid voltages }\end{array}$ & 28.77 & Not mentioned & 01.16 \\
\hline $\begin{array}{c}\text { Conventional DPC with classical PI controller } \\
\text { under unbalanced grid voltage }\end{array}$ & 36.90 & 11.81 & 03.25 \\
\hline $\begin{array}{c}\text { Proposed DPC with FOPID controller under } \\
\text { unbalanced grid voltage }\end{array}$ & 36.90 & 03.04 & 05.10 \\
\hline
\end{tabular}

\section{CONCLUSION}

In this paper, an advanced DPC based on the principle of disturbance rejection for a multifunctional grid-connected PV system equipped with active power filtering is investigated. Its main role is to improve the power quality of the healthy and infected electrical network. This control strategy requires no active and reactive power references to reject the influences of perturbations distorting the network and maintains acceptable total harmonic distortion of the source current under balanced, unbalanced, and disturbed grid voltage conditions, comparatively to the conventional DPC method. Moreover, in the proposed DPC strategy, the active power and the maximal current are delivered thanks to the FOPID controller acting instead of the standard PI regulator. Besides, fuzzy logic control has been applied to track and maintain the MPP of PV system even under rapidly increasing and decreasing irradiance. The simulation results from MATLAB/Simulink for the proposed DPC strategy show superior performance and efficiency in terms of current THD. Similarly, smaller overshoots and drops in voltage, together with shorter response time, are recorded during irradiation changes compared to those obtained from the conventional DPC with a standard PI controller.

\section{REFERENCES}

Aissa, O., Moulahoum, S., Colak, I., Babes, B. \& Kabache, N. 2018. Analysis and experimental evaluation of shunt active power filter for power quality improvement based on predictive direct power control. Environmental Science and Pollution Research, 25(25): 24548-24560.

Aissa, O., Moulahoum, S., Colak, I., Babes, B. \& Kabache, N. 2016. Improved performance and power quality of direct torque control of asynchronous motor by using intelligent controllers. Electric Power Components and Systems, 44(4): 343-358.

Algazar, M.M., AL-monier, H., EL-halim, H.A. \& Salem, M.E.E.K. 2012. Maximum power point tracking using fuzzy logic control. Electrical Power and Energy Systems, 39(1): 21-28.

Altas, I.H. \& Sharaf, A.M. 2008. A novel maximum power fuzzy logic controller for photovoltaic solar energy systems. Renewable Energy, 33(3): 388-399. 
Altin, N. \& Ozdemir, S. 2013. Three-phase three-level grid interactive inverter with fuzzy logic based maximum power point tracking controller. Energy Conversion and Management, 69: 17-26.

Benlahbib, B., Bouarroudj, N., Mekhilef, S., Abdelkrim, T., Lakhdari, A. \& Bouchafaa, F. 2018. A Fuzzy Logic Controller Based on Maximum Power Point Tracking Algorithm for Partially Shaded PV Array-Experimental Validation. Electronika ir Electrotechnika, 24(4): 1392-1215.

Bengourina, M.R., Rahli, M., Slami, S. \& Hassaine, L. 2018. PSO based direct power control for a multifunctional grid connected photovoltaic system. International Journal of Power Electronics and Drive System, 9(2): 610-621.

Bettou, K. \& Charef, A. 2009. Control quality enhancement using fractional $\mathrm{PI}^{\lambda} \mathrm{D}^{\mu}$ controller. International Journal of Systems Science, 40(8): 875-888.

Biricik, S., Redif, S., Ozerdem, Ö.C., Khadem, S.K. \& Basu, M.2014. Real-time control of shunt active power filter under distorted grid voltage and unbalanced load condition using self-tuning filter. IET Power Electronics, 7(7): 1895-1905.

Bouafia, A., Gaubert, J.P. \& Chaoui, A. 2012. Direct power control scheme based on disturbance rejection principle for threephase PWM AC/DC converter under different input voltage conditions. Journal of Electrical Systems, 8(4): 367-383.

Boukezata, B., Chaoui, A., Gaubert, J.P. \& Hachemi, M. 2016. An improved fuzzy logic control MPPT based P\&O method to solve fast irradiation change problem. Journal of Renewable and Sustainable Energy, 8(4): 043505-1-043505-14.

Boukezata, B., Gaubert, J.P., Chaoui, A. \& Hachemi, M. 2016. Predictive current control in multifunctional grid connected inverter interfaced by PV system. Solar Energy, 139: 130-141.

Chaoui, A., Gaubert, J.P. \& Bouafia, A. 2013. Experimental validation of new direct power control switching table for shunt active power filter. IEEE International Conference on Power Electronics and Applications.

Chaoui, A., Gaubert, J.P. \& Krim, F. 2010. Power quality improvement using DPC controlled three-phase shunt active filter. Electric Power Systems Research, 80(6): 657-666.

Chauhan, S.K., Shah, M.C., Tiwari, R.R. \& Tekwani, P.N. 2014. Analysis, design and digital implementation of a shunt active power filter with different schemes of reference current generation. IET Power Electronics, 7(3): 627-639.

Gorripotu, T.S., Sahu, R.K. \& Panda, S. 2015. AGC of a multi-area power system under deregulated environment using redox flow batteries and interline power flow controller. Engineering Science and Technology an International Journal, 18(4): 555-578.

Ishaque, K. \& Salam, Z. 2013. A review of maximum power point tracking techniques of PV system for uniform insolation and partial shading condition. Renewable and Sustainable Energy Reviews, 19: 475-488.

Kjær, S.B. 2012. Evaluation of the hill climbing and the incremental conductance maximum power point trackers for photovoltaic power systems. IEEE Transactions on Energy Conversion, 27(4): 922-929.

Krama, A., Zellouma, L. \& Rabhi, B. 2017. Anti-windup proportional integral strategy for shunt active power filter interfaced by photovoltaic system using technique of direct power control. Revue Roumaine des Sciences Techniques Series Electrotechnique et Energetique, 62(3): 252-257.

Malinowski, M., Jasinski, M. \& Kazmierkowski, M.P. 2004. Simple Direct Power Control of Three-Phase PWM Rectifier Using Space Vector Modulation. IEEE Transactions on Industrial Electronics, 51(2): 447-454.

Noguchi, T., Tomiki, H., Kondo, S. \& Takahashi, I. 1998. Direct power control of PWM converter without power-source voltage sensors. IEEE Transactions Industry Applications, 34(3): 473-479.

Noroozian, R. \& Gharehpetian, G.B. 2013. An investigation on combined operation of active power filter with photovoltaic arrays. International Journal of Electrical Power \& Energy Systems, 46: 392-399.

Ouchen, S., Betka, A., Abdeddaim, S. \& Menadi, A. 2016. Fuzzy-predictive direct power control implementation of a grid connected photovoltaic system, associated with an active power filter. Energy Conversion and Management, 122: 515-525.

Oustaloup, A. 1983. Systèmes asservis linéaires d'ordre fractionnaire. Masson Paris.

Oustaloup, A. 1995. La dérivation non entière: théorie, synthèse et applications. Paris.

Oustaloup,A., Levron, F., Mathieu, B. \& Nanot, F. M. 2000. Frequency-Band Complex Non integer Differentiator: Characterization and Synthesis. IEEE transactions on circuits and systems-I: fundamental theory and applications, 47(1): 25-39. 
Oustaloup, A., Mathieu, B. \& Lanusse, P. 1995. The CRONE control of resonant plants: Application to a flexible transmission. European Journal of Control, 1(2): 113-121.

Rayalla, R., Ambati, R.S. \& Gara, B.U.B. 2019. An Improved Fractional Filter Fractional IMC-PID Controller Design and Analysis for Enhanced Performance of Non-integer Order Plus Time Delay Processes. European Journal of Electrical Engineering, 21(2): 139-147.

Sarra, M., Djazia, K., Chaoui, A. \& Krim, F. 2009. Three-phase Active Power Filter with Integrator-Proportional control. Journal of Electrical Systems, 1: 79-84.

Sarra, M., Gaubert, J.P., Chaoui, A. \& Krim, F. 2011. Experimental validation of two control techniques applied to a three phase shunt active power filter for power quality improvement. International Review of Electrical Engineering, 6(6): 2825-2836.

Sondhi, S. \& Hote, Y.V. 2014. Fractional order PID controller for load frequency control. Energy Conversion and Management 85: 343-353.

Tareen, W.U., Mekhilef, S., Seyedmahmodian, M. \& Horan, B. 2017. Active power filter (APF) for mitigation of power quality issues in grid integration of wind and photovoltaic energy conversion system. Renewable and Sustainable Energy Reviews, 70: $635-655$.

Zadeh, L.A. 1965. Fuzzy sets. Conference on Information and Control.

Zhang, Y., Peng, Y. \& Qu, C. 2016. Model predictive control and direct power control for PWM rectifiers with active power ripple minimization. IEEE Transactions on Industry Applications, 52(6): 4909-4918. 